\title{
Root Canal Morphology of Maxillary First and Second Molars in a Qatari Population: A Cone-Beam Computed Tomography Study
}

\author{
Maryam Mohammed Al-Obaid ${ }^{1}$ Fatima Abdullah Al-Sheeb ${ }^{1}$ \\ ${ }^{1}$ Hamad Medical Corporation, Hamad Dental Centre, Doha, Qatar \\ Address for correspondence Maryam Mohammed Al-Obaid, DDS, \\ DMS, Hamad Medical Corporation, Hamad Dental Centre, Doha, \\ Qatar (e-mail: malobaid@hamad.qa).
}

Eur Dent Res Biomater J 2021;2:34-38.

\begin{abstract}
Keywords

- Qatari population

- maxillary molars

- morphology

Objective The purpose of this study was to evaluate the number of roots and canal configuration of maxillary first and second molars in Qatari population.

Materials and Methods A total of 544 cone-beam computed tomography (CBCT) records of Qatari patients were included in this study. The CBCT images were reviewed by two endodontists. The age, sex, bilateral symmetry, root number, and canal configuration according to Vertucci were tabulated.

Results About $97.5 \%$ maxillary first molars had three roots and $2.5 \%$ had two roots. Maxillary second molar showed $88.2 \%$ three roots, $7.3 \%$ two roots, $3.3 \%$ single root, and $1.2 \%$ four roots. For maxillary first molars, the most common Vertucci classifications for the mesiobuccal root were type IV (2-2, 35.9\%) and type II (2-1, 21.1\%). For maxillary second molars, the most common Vertucci classifications for the mesiobuccal root were type IV (2-2, 27\%), type III (1-2-1, 21.3\%), type I (1, 19.6\%), and type II $(2-1,18.9 \%)$. In maxillary first molar, $53.1 \%$ right is different from the left and in maxillary second molars, $60.2 \%$ right is different from the left.

Conclusions In Qatari population, three roots are common in maxillary molars. Mesiobuccal root of maxillary first molars is predominant with Vertucci type IV (2-2) and type II (2-1). Maxillary second molars showed variable Vertucci classification. High bilateral asymmetry was found in canal configuration of the same individuals that should be considered during root canal treatment of two opposite molars.
\end{abstract}

\section{Introduction}

Successful root canal therapy depends on thorough debridement and complete obturation of the root canal system. ${ }^{1}$ For this to be achieved, it is necessary to locate all root canals. The inability to locate and consequently treat all these canals will lead to posttreatment disease. ${ }^{2,3}$ A clinician should be aware of the internal morphology of the teeth and the wide range of anatomical variations possibly encountered during the root canal therapy.

The root canal system of the maxillary first and second molars is usually complex and variable., ${ }^{2,4,5}$ The mesiobuccal root was reported to be showing the most variations especially regarding the prevalence of a second mesiobuccal canal and the types of canal configurations.,4-11 Certain factors contribute to the wide variations reported in the incidence
DOI https://doi.org/ $10.1055 / \mathrm{s}-0041-1731625$ (c) 2021. European Dental Research and Biomaterials Journal.

This is an open access article published by Thieme under the terms of the Creative Commons Attribution-NonDerivative-NonCommercial-License, permitting copying and reproduction so long as the original work is given appropriate credit. Contents may not be used for commercial purposes, or adapted, remixed, transformed or built upon. (https://creativecommons.org/licenses/by-nc-nd/4.0/).

Thieme Medical and Scientific Publishers Pvt. Ltd. A-12, 2nd Floor, Sector 2, Noida-201301 UP, India 
of second mesiobuccal canal in maxillary molars and these include race, age, and gender of the population studied. ${ }^{4-18}$

The introduction of cone-beam computed tomography (CBCT) has significantly improved the understanding of root canal morphology. ${ }^{19}$ The advantages of CBCT scans are nondestructive way to study root canal morphology at lower radiation doses and higher resolution compared with other methods that studied the root canal anatomy of human teeth which make it more favorable for clinical application as well as a reliable method of research. ${ }^{20-22}$

The aim of this study was to identify the root canal morphology of the maxillary first and second molars in Qatari population using $\mathrm{CBCT}$ imaging in vivo.

\section{Materials and Methods}

This retrospective descriptive study was performed with the approval of the Medical Research Center and the Institutional Review Board at Hamad Medical Corporation in Doha, Qatar. The study population is a sample of the Qatari population, who were referred for dental treatment. A total of 544 CBCT records of Qatari patients who attended Hamad Dental services were included in this study. The CBCT images were requested for different treatment purposes including examination, diagnosis, or treatment planning, and they were performed by expert radiologists. I-CT CBCT scanner (Imaging Sciences International, Hatfield, Pennsylvania, United States) was used operated with $120 \mathrm{kVp}$ (eff) tube voltage, $20 \mathrm{~mA}$ tube current, 14.7 second, Voxel size 0.4 to $0.2 \mathrm{~mm}$, with field of view of $160 \times 40 \mathrm{~mm}$.

The CBCT images were reviewed by two endodontists with more than 10 years of clinical experience independently. The images were scrutinized through the sagittal, coronal, and axial views, and three-dimensional reconstruction of the jaws was applied when needed using Infinite software version 11.4 and Xelis dental three-dimensional viewer software version 1.0 (Infinitt, Seoul, South Korea) to extract the wanted information. In the beginning, $20 \%$ of the sample was viewed by each viewer alone twice and with 3 weeks apart, and the data collected were used to measure interexaminer and intraexaminer agreement.

For the data collection, patient's identification was not revealed where each patient was given a specific code. The data collection was as follows: age and gender of the patient, inclusion or exclusions and the reason of exclusion, each tooth type and location, the number of roots, canal configuration type according to Vertucci classification ${ }^{1}$; in addition to incidental findings such as the presence of anatomical variations, congenital anomalies, or pathologic changes.

The teeth included in this study were selected according to the following criteria: (1) permanent teeth with fully formed root; (2) no intracanal or extraradicular restorations; (3) no apical pathosis; (4) no calcification of the canals or resorption, and (5) clear CBCT images with no artifact. When one of these criteria was not applicable, the teeth were excluded mentioning the reason.

The statistical analysis was performed using Statistical Product and Service Solutions (SPSS), version 20 (SPSS Inc, Chicago, Illinois, United States). A descriptive analysis was implemented in this study to describe a detailed characteristic of the root anatomy and root canal configuration of the permanent teeth including frequency, percentages, and mean. Chi-squared test was used to compare right teeth to the left. Kappa agreement analysis was performed to assess the interexaminer and intraexaminer agreement.

\section{Results}

A total of 544 CBCT records were evaluated that included 1,088 examined teeth. The interexaminer agreement result was $95.13 \%$ (range: $74-100 \%$ ) and the intraexaminer agreement was $91.7 \%$ (range: $87.4-98.1 \%$ ).

Out of 1,088 examined teeth, 277 maxillary first molars teeth were included $(25 \%)$ in this study.

One-hundred sixty-one (58.2\%) teeth belong to females, while $116(41.9 \%)$ teeth belong to males. The average age was 32.2 years (range: 10-70). The number of roots most commonly observed were three roots in 270 teeth (97.5\%). Only seven teeth $(2.5 \%)$ had two roots, and in three teeth, the roots were located in buccal and palatal position, while in 4 teeth, the roots were located in mesial and distal position ( - Table 1).

The root canal configuration of maxillary first molar, Vertucci type I classification was always observed in the palatal root $(100 \%)$ and most of the distobuccal root (97\%) except for eight teeth, five (1.9\%) had Vertucci type III and three (1.1\%) had type V classification. Different Vertucci classifications were observed in the mesiobuccal root, in which Vertucci type IV was the predominant configuration (35.9\%) followed by type II (21.1\%), type III (17\%), type I (12.9\%), type

Table 1 Summary of gender, age, and root number of maxillary first and second molars

\begin{tabular}{|l|l|l|l|l|l|l|l|l|l|}
\hline Tooth type & $\begin{array}{l}\text { No. of } \\
\text { patients } \\
\text { included } \\
(\%)\end{array}$ & $\begin{array}{l}\text { No. of } \\
\text { patient } \\
\text { excluded } \\
(\%)\end{array}$ & $\begin{array}{l}\text { Female } \\
(\%)\end{array}$ & Male (\%) & Age mean & $\begin{array}{l}\mathbf{4} \text { roots } \\
\text { (\%) }\end{array}$ & $\begin{array}{l}\mathbf{3} \text { roots } \\
\text { (\%) }\end{array}$ & $\begin{array}{l}\mathbf{2} \text { roots } \\
\text { (\%) }\end{array}$ & $\begin{array}{l}\mathbf{1} \text { root } \\
(\%)\end{array}$ \\
\hline $\begin{array}{l}\text { Maxillary } \\
\text { first molar }\end{array}$ & $\begin{array}{l}277 \text { out of } \\
1,088(25.5)\end{array}$ & $811(74.5)$ & $161(58.2)$ & $116(41.9)$ & $32.2(10-70)$ & 0 & $270(97.5)$ & $7(2.5)$ & 0 \\
\hline $\begin{array}{l}\text { Maxillary } \\
\text { second } \\
\text { molar }\end{array}$ & $\begin{array}{l}330 \text { out of } \\
1,088(30.3)\end{array}$ & $758(69.7)$ & $207(62.7)$ & $123(37.3)$ & $32.5(12-69)$ & $4(1.2)$ & $291(88.2)$ & $24(7.3)$ & $11(3.3)$ \\
\hline
\end{tabular}


V (9.3\%), and type VI (2.6\%). Three (1.2\%) mesiobuccal roots had complex anatomy. Two rooted maxillary first molars with buccal and palatal roots and one of which had mesial and distal root had Vertucci type I classification in all the roots. Two mesial roots had type III and one root had type IV. Three distal roots had type IV (-Table 2).

The comparison between the upper right and left maxillary first molars in the same individuals found to be symmetrical in $96.9 \%$ and dissimilar in $3.1 \%$, while the root canal configuration was found to be symmetrical in $46.9 \%$ and asymmetrical in $53.1 \%$ (-Table $\mathbf{3})$.

For maxillary second molar, 330 teeth $(30.3 \%)$ were included, in which $62.7 \%$ of teeth belong to females and $37.3 \%$ of teeth belong to males. The age ranged from 12 to 69 years with an average of 32.5 years. The number of the roots most commonly observed were three $(88.2 \%)$, two $(7.3 \%)$, one (3.3\%), and four roots (1.2\%) (-Table 1). The two rooted maxillary second molars were found to be either in mesial and distal or buccal and palatal position.

In the three rooted maxillary second molars, the root canal configuration was mainly Vertucci type I classification in the palatal root (99.7\%) except for one palatal root that had type V. Distobuccal roots were type I (99.3\%) except for two distobuccal roots that had Vertucci type III. Mesiobuccal root showed almost all different types of Vertucci classification and the most predominant types were type IV (27\%), type III (21.3\%), type I (19.6\%), type II (18.9\%), followed by type V (9.3\%), type VI (3.1\%), and type VII (0.7\%). The two rooted maxillary second molars with buccal and palatal roots showed Vertucci type I classification in all palatal and nine buccal roots, three buccal roots showed type III and three buccal roots showed type $\mathrm{V}$, two buccal roots showed type II, and one buccal root showed complex canal configuration. In the four rooted maxillary second molars, Vertucci type I classification was predominant in all the canals except in one mesiobuccal root that was type II. Four teeth with single root second molar were type II, three teeth type I, two type VIII, and one showed complex anatomy (- Table 4).

The number of roots in maxillary second molars in the right and left were symmetrical in $89.4 \%$ and dissimilar in $10.6 \%$, while the root canal configuration was symmetrical in $39.8 \%$ and asymmetrical in $60.2 \%$ (-Table 3 ).

\section{Discussion}

The aim of this study was to provide detailed root canal morphology of the maxillary first and second molars in Qatari population based on a retrospective analysis of CBCT images. The study revealed that the predominant number of roots in the maxillary first molars was three (97.5\%) while (2.5\%) of the first molars with two roots. The results are consistent with previous findings of different populations., ${ }^{4,6,7,9,12}$ The maxillary second molar showed more variations in root number with the majority of three roots in $88.2 \%$. However, three other variants were observed in the maxillary second molars; two roots (7.3\%), one root (3\%), and four roots (1.2\%) were less frequently observed. This is common finding in many studies of root canal anatomy. ${ }^{5,7,16}$

Understanding the correct number of roots and canal morphology is essential in root canal therapy. Accurate knowledge of possible variations in root canal system before root canal therapy is crucial for endodontists with high rates of variation in maxillary molars. In line with other studies, $5,7,10,18,23,24$ mesiobuccal roots of maxillary first and second molar teeth had more variation in their root canal configuration compared with distobuccal and palatal roots that had been mostly one canal in this study. The incidence of two separated canals, Vertucci type IV, was $35.9 \%$ of the maxillary first molar and $21.1 \%$ started with two canals even if it will rejoin somewhere in the root trunk, Vertucci type II. It was demonstrated that root canal treatment of maxillary molars has the highest rates of clinical failure probably because complexity in root canal anatomy and not easily detected during root canal treatment. ${ }^{24-28}$ Wolcott et al examined 3,578 root canals treated first molars during a 5-year period and found that the overall prevalence of second mesiobuccal canal was $60 \%$ suggesting that failure to find and treat existing second canal will decrease the long-term prognosis. As a result, these anatomic variations should be considered during root canal treatment of maxillary molars. ${ }^{28}$ The important factors

Table 2 Number and percentage of root canal system in maxillary first molar

\begin{tabular}{|c|c|c|c|c|c|c|c|c|c|}
\hline $\begin{array}{l}\text { Maxillary } \\
\text { first } \\
\text { molar }\end{array}$ & Root & $\begin{array}{l}\text { Type I (1), } \\
n(\%)\end{array}$ & $\begin{array}{l}\text { Type II (2-1), } \\
n \text { (\%) }\end{array}$ & $\begin{array}{l}\text { Type III } \\
(1-2-1), \\
n(\%)\end{array}$ & $\begin{array}{l}\text { Type IV } \\
(2-2), n \\
(\%)\end{array}$ & $\begin{array}{l}\text { Type V } \\
(1-2), n \\
(\%)\end{array}$ & $\begin{array}{l}\text { Type VI } \\
(2-1-2), n \\
(\%)\end{array}$ & $\begin{array}{l}\text { Complex } \\
\text { anatomy }\end{array}$ & \\
\hline \multirow[t]{3}{*}{3 roots } & $\mathrm{MB}$ & 35 (12.9) & $57(21.1)$ & $46(17)$ & $97(35.9)$ & $25(9.3)$ & $7(2.6)$ & \multirow[t]{3}{*}{$3(1.1)$} & $2-1-2-1^{a}$ \\
\hline & DB & $262(97)$ & $0(0)$ & $5(1.9)$ & 0 & $3(1.1)$ & $0(0)$ & & $2-1-2-1-2^{a}$ \\
\hline & $P$ & 100 & 0 & 0 & 0 & 0 & 0 & & $2-3-1^{a}$ \\
\hline \multirow[t]{4}{*}{2 roots } & B & 3 & 0 & 0 & 0 & 0 & 0 & & \\
\hline & $P$ & 3 & 0 & 0 & 0 & 0 & 0 & & \\
\hline & $M$ & 1 & 0 & 2 & 1 & 0 & 0 & & \\
\hline & D & 1 & 0 & 0 & 3 & 0 & 0 & & \\
\hline
\end{tabular}

Abbreviations: B, buccal; D, distal; DB, distobuccal; M, mesial; MB, mesiobuccal; P, palatal.

${ }^{a}$ Complex anatomy of mesiobuccal root. 
Table 3 Symmetry of maxillary first and second molars

\begin{tabular}{|l|l|l|l|l|l|}
\hline $\begin{array}{l}\text { Maxillary first } \\
\text { molar }\end{array}$ & Symmetry & Asymmetry & $\begin{array}{l}\text { Maxillary second } \\
\text { molar }\end{array}$ & Symmetry & Asymmetry \\
\hline Root number & $\begin{array}{l}96.9 \% \text { Rt and Lt } \\
\text { the same }\end{array}$ & $\begin{array}{l}\text { 3.1\% Rt and Lt } \\
\text { different }\end{array}$ & Root number & $\begin{array}{l}89.4 \% \text { Rt and Lt } \\
\text { the same }\end{array}$ & $10.6 \%$ Rt and Lt different \\
\hline $\begin{array}{l}\text { Root canal } \\
\text { configuration }\end{array}$ & $\begin{array}{l}46.9 \% \text { Rt and Lt } \\
\text { the same }\end{array}$ & $\begin{array}{l}53.1 \% \text { Rt and Lt } \\
\text { different }\end{array}$ & $\begin{array}{l}\text { Root canal } \\
\text { configuration }\end{array}$ & $\begin{array}{l}39.8 \% \text { Rt and Lt } \\
\text { the same }\end{array}$ & $60.2 \%$ Rt and Lt different \\
\hline
\end{tabular}

Abbreviations: Lt, left; Rt, right.

Table 4 Number and percentage of root canal system in maxillary second molar

\begin{tabular}{|c|c|c|c|c|c|c|c|c|c|c|c|}
\hline $\begin{array}{l}\text { Maxillary } \\
\text { second } \\
\text { molar }\end{array}$ & Root & $\begin{array}{l}\text { Type I } \\
(1), n(\%)\end{array}$ & $\begin{array}{l}\text { Type II } \\
(2-1), n \\
(\%)\end{array}$ & $\begin{array}{l}\text { Type III } \\
(1-2-1), n \\
(\%)\end{array}$ & $\begin{array}{l}\text { Type IV } \\
(2-2), n \\
(\%)\end{array}$ & $\begin{array}{l}\text { Type V } \\
(1-2), n \\
(\%)\end{array}$ & $\begin{array}{l}\text { Type VI } \\
(2-1- \\
2), n \\
(\%)\end{array}$ & $\begin{array}{l}\text { Type } \\
\text { VII } \\
(1-2- \\
1-2), n \\
(\%)\end{array}$ & $\begin{array}{l}\text { Type } \\
\text { VIII } \\
(3), n \\
(\%)\end{array}$ & $\begin{array}{l}\text { Complex } \\
\text { anatomy }\end{array}$ & \\
\hline \multirow[t]{3}{*}{3 roots } & MB & 57 (19.6) & 55 (18.9) & $62(21.3)$ & $79(27)$ & $27(9.3)$ & $9(3.1)$ & $2(0.7)$ & $0(0)$ & & \\
\hline & DB & 289 (99.3) & $0(0)$ & $2(0.7)$ & $0(0)$ & $0(0)$ & $0(0)$ & $0(0)$ & $0(0)$ & & \\
\hline & $P$ & $290(99.7)$ & $0(0)$ & $0(0)$ & $0(0)$ & $1(0.3)$ & $0(0)$ & $0(0)$ & $0(0)$ & & \\
\hline \multirow[t]{4}{*}{2 roots } & $M$ & $0(0)$ & $0(0)$ & $1(4)$ & $4(16.6)$ & $0(0)$ & $0(0)$ & $0(0)$ & $1(4 \%)$ & \multirow[t]{4}{*}{1} & \multirow[t]{4}{*}{ B2-1-3-2 } \\
\hline & D & $5(20.8)$ & $0(0)$ & $0(0)$ & $1(4)$ & $0(0)$ & $0(0)$ & $0(0)$ & $0(0)$ & & \\
\hline & B & $9(37)$ & $2(8)$ & $3(12)$ & $0(0)$ & $3(12)$ & $0(0)$ & $0(0)$ & $0(0)$ & & \\
\hline & $P$ & $18(75)$ & $0(0)$ & $0(0)$ & $0(0)$ & $0(0)$ & $0(0)$ & $0(0)$ & $0(0)$ & & \\
\hline \multirow[t]{2}{*}{4 roots } & MB & 3 & 1 & $0(0)$ & $0(0)$ & $0(0)$ & $0(0)$ & $0(0)$ & $0(0)$ & & \\
\hline & $\begin{array}{l}\text { DB } \\
\text { MP } \\
\text { DP }\end{array}$ & 4 & $0(0)$ & $0(0)$ & $0(0)$ & $0(0)$ & $0(0)$ & $0(0)$ & $0(0)$ & & \\
\hline One root & & 3 & 4 & 1 & $0(0)$ & $0(0)$ & $0(0)$ & $0(0)$ & 2 & 1 & $2-3^{b}$ \\
\hline
\end{tabular}

Abbreviations: B, buccal; D, distal; DB, distobuccal; M, mesial; MB, mesiobuccal; MP, mesiopalatal; P, palatal.

${ }^{a}$ Complex anatomy of Buccal root.

${ }^{\mathrm{b}}$ Complex anatomy of single root maxillary second molar.

that help in treating second mesiobuccal canal in routine practice is the clinician's knowledge of its presence and always allocating sufficient time and use of sophisticated tools to locate these canals. It has been observed that mesiobuccal root of the maxillary second molar represents technical challenge for the clinician with substantial variations in root canal anatomy. In the present study, almost all Vertucci type classifications were detected particularly in this root (-Table 4).

There are few studies that have compared the right and left teeth of the same individual. ${ }^{29-32}$ In the present study, it was interesting to find out that more than half of root canal configuration of maxillary first and second molars were not alike in both sides of the same patient (53.1 and $60.2 \%$ ). These data are important from a clinical perspective as these variations in symmetry should be considered when treating two opposite molars in the same patient.

\section{Conclusion}

In vivo $\mathrm{CBCT}$ study showed that Qatari population has a higher prevalence of three roots in first and second molars. The root canal configuration of the maxillary first and second molars was variable. The incidence of two canals in the mesiobuccal root was higher in the maxillary first molar than in maxillary second molar. High bilateral asymmetry was found in configuration of canals in the same individuals. These variations should be taken into consideration during root canal treatment.

\section{Conflict of Interest}

None declared.

\section{References}

1 Vertucci FJ. Root canal anatomy of the human permanent teeth. Oral Surg Oral Med Oral Pathol 1984;58(5):589-599

2 Weine FS, Healey HJ, Gerstein H, Evanson L. Canal configuration in the mesiobuccal root of the maxillary first molar and its endodontic significance. Oral Surg Oral Med Oral Pathol 1969;28(3):419-425

3 Friedman S. Prognosis of initial endodontic therapy. Endod Topics 2002;2(1):59-88

4 Cleghorn BM, Christie WH, Dong CC. Root and root canal morphology of the human permanent maxillary first molar: a literature review. J Endod 2006;32(9):813-821

5 Peikoff MD, Christie WH, Fogel HM. The maxillary second molar: variations in the number of roots and canals. Int Endod J 1996;29(6):365-369

6 Zheng QH, Wang Y, Zhou XD, Wang Q, Zheng GN, Huang DM. A cone-beam computed tomography study of maxillary first permanent molar root and canal morphology in a Chinese population. J Endod 2010;36(9):1480-1484 
7 Neelakantan P, Subbarao C, Ahuja R, Subbarao CV, Gutmann JL. Cone-beam computed tomography study of root and canal morphology of maxillary first and second molars in an Indian population. J Endod 2010;36(10):1622-1627

$8 \mathrm{Ng}$ YL, Aung TH, Alavi A, Gulabivala K. Root and canal morphology of Burmese maxillary molars. Int Endod J 2001;34(8):620-630

9 Alavi AM, Opasanon A, Ng YL, Gulabivala K. Root and canal morphology of Thai maxillary molars. Int Endod J 2002;35(5):478-485

10 AlNazhan S. The prevalence of two canals in mesial root of endodontically treated maxillary first molars among a Saudi Arabian sub-population. Saudi Dent J 2005;17(1):24-28

11 al Shalabi RM, Omer OE, Glennon J, Jennings M, Claffey NM. Root canal anatomy of maxillary first and second permanent molars. Int Endod J 2000;33(5):405-414

12 Kim Y, Lee SJ, Woo J. Morphology of maxillary first and second molars analyzed by cone-beam computed tomography in a Korean population: variations in the number of roots and canals and the incidence of fusion. J Endod 2012;38(8):1063-1068

13 Thomas RP, Moule AJ, Bryant R. Root canal morphology of maxillary permanent first molar teeth at various ages. Int Endod J 1993;26(5):257-267

14 Zhang R, Yang H, Yu X, Wang H, Hu T, Dummer PM. Use of $\mathrm{CBCT}$ to identify the morphology of maxillary permanent molar teeth in a Chinese subpopulation. Int Endod J 2011;44(2):162-169

15 Pattanshetti N, Gaidhane M, Al Kandari AM. Root and canal morphology of the mesiobuccal and distal roots of permanent first molars in a Kuwait population-a clinical study. Int Endod J 2008;41(9):755-762

16 Alamri HM, Mirza MB, Riyahi AM, Alharbi F, Aljarbou F. Root canal morphology of maxillary second molars in a Saudi sub-population: a cone beam computed tomography study. Saudi Dent J 2020;32(5):250-254

17 Weine FS, Hayami S, Hata G, Toda T. Canal configuration of the mesiobuccal root of the maxillary first molar of a Japanese sub-population. Int Endod J 1999;32(2):79-87

18 Martins JNR, Gu Y, Marques D, Francisco H, Caramês J. Differences on the root and root canal morphologies between Asian and White Ethnic Groups analyzed by cone-beam computed tomography. J Endod 2018;44(7):1096-1104

19 Tachibana H, Matsumoto K. Applicability of X-ray computerized tomography in endodontics. Endod Dent Traumatol 1990;6(1):16-20

20 Cotton TP, Geisler TM, Holden DT, Schwartz SA, Schindler WG. Endodontic applications of cone-beam volumetric tomography. J Endod 2007;33(9):1121-1132
21 Blattner TC, George N, Lee CC, Kumar V, Yelton CD. Efficacy of cone-beam computed tomography as a modality to accurately identify the presence of second mesiobuccal canals in maxillary first and second molars: a pilot study. J Endod 2010;36(5):867-870

22 Matherne RP, Angelopoulos C, Kulild JC, Tira D. Use of cone-beam computed tomography to identify root canal systems in vitro. J Endod 2008;34(1):87-89

23 Lee JH, Kim KD, Lee JK, et al. Mesiobuccal root canal anatomy of Korean maxillary first and second molars by cone-beam computed tomography. Oral Surg Oral Med Oral Pathol Oral Radiol Endod 2011;111(6):785-791

24 Baratto Filho F, Zaitter S, Haragushiku GA, de Campos EA, Abuabara A, Correr GM. Analysis of the internal anatomy of maxillary first molars by using different methods. J Endod 2009;35(3):337-342

25 Kharouf N, Mancino D. An In Vivo study: location and instrumentation of the second mesiobuccal canal of the maxillary second molar. J Contemp Dent Pract 2019;20(2):131-135

26 Coelho MS, Lacerda MFLS, Silva MHC, Rios MA. Locating the second mesiobuccal canal in maxillary molars: challenges and solutions. Clin Cosmet Investig Dent 2018;10:195-202

27 Ibarrola JL, Knowles KI, Ludlow MO. McKinley IB Jr. Factors affecting the negotiability of second mesiobuccal canals in maxillary molars. J Endod 1997;23(4):236-238

28 Chang SW, Lee JK, Lee Y, Kum KY. In-depth morphological study of mesiobuccal root canal systems in maxillary first molars: review. review. Restor Dent Endod 2013;38(1):2-10

29 Wolcott J, Ishley D, Kennedy W, Johnson S, Minnich S, Meyers J. A 5 year clinical investigation of second mesiobuccal canals in endodontically treated and retreated maxillary molars. J Endod 2005;31(4):262-264

30 Felsypremila G, Vinothkumar TS, Kandaswamy D. Anatomic symmetry of root and root canal morphology of posterior teeth in Indian subpopulation using cone beam computed tomography: a retrospective study. Eur J Dent 2015;9(4):500-507

31 Plotino G, Tocci L, Grande NM, et al. Symmetry of root and root canal morphology of maxillary and mandibular molars in a white population: a cone-beam computed tomography study in vivo. J Endod 2013;39(12):1545-1548

32 Mashyakhy M, Chourasia HR, Halboub E, Almashraqi AA, Khubrani Y, Gambarini G. Anatomical variations and bilateral symmetry of roots and root canal system of mandibular first permanent molars in Saudi Arabian population utilizing cone- beam computed tomography. Saudi Dent J 2019;31(4):481-486 